\title{
Enhancement of Conventional Glass-Ionomer Cement by Nanozirconia- Hydroxyapatite-Silica
}

\author{
Wan Zaripah Wan Bakar* \\ Consultant Prosthodontist, School of Dental Sciences, Universiti Sains Malaysia, Malaysia \\ *Corresponding author: Wan Zaripah Wan Bakar, Senior Lecturer and Consultant Prosthodontist, School of Dental Sciences, USM Health Campus, \\ Universiti Sains Malaysia, 16150 , Kubang Kerian, Kelantan, Malaysia
}

Submission: 眥July 17, 2017; Published: 眥 August 07, 2017

\section{Opinion}

Since decades ago improvement of materials is always the aims of researchers to fulfill needs in many areas such as engineering, biomedical and also dentistry. Glass-ionomer-cement (GIC) is one of the most commonly used materials in dentistry where it is highly used as restoration in deciduous teeth and as lining material or temporary restoration for adult. The conventional GIC (cGIC) was introduced in 1972 [1] which is an acid-base material and the latter type is with addition of HEMA that is cured by light, called resin modified GIC. Conventional GIC is well liked due to its properties including anticariogenic, good adhesion to tooth structure, biocompatible, ability to release and reservoir fluoride and easy to handle [2]. Despite, it is limited by weaknesses such as low hardness, easily worn down and too opaque. Due to this limitation many studies had been done aiming to enhance and improve GIC by modification or addition of material such silver-cermet, stainless steel powder, titanium dioxide, silver tin alloy, carbon and aluminasilicate fibers [2-5].

A number of studies have been carried out to evaluate the effect of the addition of HA powders to restorative dental materials such as glass ionomer cement (GIC) and composite resin [6,7]. In a study by Moshaverinia et al. incorporation of hydroxyapatite and fluoroapatite nanobioceramics into conventional glass ionomer cements was found improved the mechanical prand bond strength to dentin [6]. Different study used bioactive glass and result shown that there is an increase of surface micro hardness of the cGIC [8]. An addition of highly crystalline HA/ZrO2 into GIC especially the composition of 4 and 12 volume exhibited superior mechanical properties than the original GICs [9]. In 2014, a study done by Rahman et al. [10] where they had incorporated nanosilica hydroxyapatite (nano-Si-HA) in the cGIC Fuji IX GP (GC International, Japan) which improved the hardness by $73 \%$. It is hypothesized that the fillers of nano-Si-HA reduce the voids in GIC, hence make it more compact and produced a stronger and harder GIC. The results obtain from Scanning Electron Microscope micrographs and magic angle spinning nuclear magnetic resonance showed good distribution of the nano-sized particles and presence of high degree of cross linking between the silica and GIC [11].

Lately, the benefit of zirconia was incorporated to further improve the cGIC. Zirconia has high mechanical performance, high fracture toughness, not cytotoxic and has low corrosion potential [12-14]. In dentistry, three types of zirconia are commonly used which are: yttrium cation-doped tetragonal zirconia polycrystals, magnesium cation-doped partially stabilized zirconia and zirconia toughened alumina [15]. It is an excellent ceramic biomaterial with a dull white color which can mask the underneath structure [16,17]. In our current study, the nano-Zr-HA-Si was added by synthesized using one-pot technique which we found that it has significantly increased the hardness of the original cGIC. The one-pot technique used was able to produce highly homogeneous nanopowder distribution with lesser agglomeration which was confirmed by SEM dot-mapping assessment. Hardness property was significantly enhanced where Vickers microhardness result showed highest value was achieved at $5 \%$ addition of GIC-nano $25 \mathrm{Zr}$-Si-HA which is $(\sim 79.38 \mathrm{HV})$ and total increment is about $54 \%$ when compared with cGIC. Furthermore, CIELAB color test revealed that the color has improved shown by an increase of color difference; $\Delta E[18]$.

As conclusion, within the limitation of the study, the incorporation of $\mathrm{Zr}$-Si-HA nanopowder is able to enhance mechanically the cGIC and also improved the aesthetics which is highly demanded nowadays.

\section{Acknowledgement}

The study was funded by USM Research University grant No. RUI 1001/PPSG/ 812164.

\section{References}

1. John FM, Angus WGW (2008) Applied Dental Materials ( $9^{\text {th }}$ edn), Oxford, Wiley-Blackwell (an imprint of John Wiley \& Sons Ltd), United Kingdom, pp. 284-287.

2. Lohbauer U (2010) Dental glass ionomer cements as permanent filling materials? -Properties, Limitations and Future Trends. Materials 3(1): 76-96. 
3. Oldfield CWB, Ellis B (1991) Fibrous Reinforcement of glass ionomer cements. Clinical Materials 7(4): 313-323.

4. Elaska SE, Hamouda IM, Swain MV (2011) Titanium dioxide nanoparticles addition to a conventional glass-ionomer restorative: Influence on physical and antibacterial properties. J Dent 39(9): 589-598.

5. Moshaverinia A, Roohpour N, Chee WWL, Schricker SR (2011) A review of powder modification in conventional glass-ionomer dental cements. Journal of Materials Chemistry 21(5): 1319-1328.

6. Moshaverinia A, Ansari S, Moshaverinia M, Roohpour N, Darr JA, et al. (2008) Effects of incorporation of hydroxyapatite and fluoroapatite nanobioceramics into conventional glass ionomer cement (GIC). Acta Biomater 4(2): 432-440.

7. Calabrese L, Fabiano F, Currò M, Borsellino C, Bonaccorsi LM, et al. (2016) Hydroxyapatite whiskers based resin composite versus commercial dental composites: Mechanical and biocompatibility characterization. Advances in Materials Science and Engineering 2016(2016): 1-9.

8. Yli-Urpo H, Lassila LV, Narhi T, Vallittu PK (2005) Compressive strength and surface characterization of glass ionomer cements modified by particles of bioactive glass. Dent Mater 21(3): 201-209.

9. Gu YW, Yap AU, Cheang P, Khor KA (2005) Effects of incorporation of HA/ ZrO2 into glass ionomer cement (GIC). Biomaterials 26(7): 713-720.

10. Rahman IA, Masudi SM, Luddin N, Sheikh RA (2014) One-pot synthesis of hydroxyapatite-silica nanopowder composite for hardness enhancement of glass ionomer cements (GIC). Bulletin of Materials Science 37(2): 213219.
11. Sheikh RA, AbRahman I, Masudi SM, Luddin N (2014) Modification of glass ionomer cement by incorporating hydroxyapatite-silica nanopowder composite: Sol-gel synthesis and characterization. Ceramic International 40(2): 3165-3170.

12. Ferrari M, Vichi A, Zarone F (2015) Zirconia abutments and restorations: From laboratory to clinical investigations. Dent Mater 31(3): e63-e76.

13. Goharshadi EK, Hadadian M (2012) Effect of calcination temperature on structural, vibrational, optical, and rheological properties of zirconia nanoparticles. Ceramics International 38(3): 1771-1777.

14. Guo GY, Chen Y-L (2005) A nearly pure monoclinic nanocrystalline zirconia. Journal of Solid State Chemistry 178(5): 1675-1682.

15. Madfa AA, Al-Sanabani FA, Al-Qudami NH, Al-Sanabani JS, Amran AG (2014) Use of zirconia in dentistry: An overview. The Open Biomaterials Journal 5: 1-9.

16. Liu X, Huang A, Ding C, Chu PK (2006) Bioactivity and cytocompatibility of zirconia (ZrO2) film fabricated by cathodic arc deposition. Biomaterials 27(21): 3904-3911.

17. Bona AD, Pecho OE, Alessandretti R (2015) Zirconia as a dental biomaterial. Materials 8(8): 4978-4991.

18. Rahman IA, Ghazali AM, WanBakar WZ, Masudi SM (2017) Modification of glass ionomer cement by incorporating nanozirconia-hydroxyapatitesilica nano-powder composite by the one-pot technique for hardness and aesthetics improvement. Ceramic International doi.org/10.1016/j. ceramint.2017.07.022. 